\title{
ДискУссии
}

DOI: https://doi.org/10.15688/jvolsu2.2021.1.13

UDC 81'42

Submitted: 03.12.2019

LBC 81.055.1-003

Accepted: 02.12.2020

\section{STRATEGIC IMPORTANCE OF VALORIZING DISCOURSE IN THE SUBJECT SPHERE OF INNOVATION}

\author{
Evgenia F. Serebrennikova \\ Irkutsk State University, Irkutsk, Russia \\ Olga N. Sadovnikova \\ Irkutsk State University, Irkutsk, Russia
}

\begin{abstract}
The article focuses on the study of strategic importance as a qualitative category of discourse, characterizing the promotion of significant meaning in an axiologically parametrized media space. As part of the discursivization trajectory model, which was justified in line with a dynamic approach to the discourse study using the methods of inferential and interpretative analysis, the strategic nature of media discourse is set. It is organized by targeted, relevant important concept of "Innovation" as well as the ways of its implementation in axiological strategies. The type of discourse topic and intentionality of promoting significant meaning in the vector from the world of real to the world of proper and desired endow this discourse with a valorizing, constructive and prescriptive character. The projected axiological strategies and tactics contribute to rethinking and enriching the structure of the concept of "Innovation". In the prevailing strategy of negative valorization, in the tactics of devalorizing evaluation nomination of innovations as a realized phenomenon, axiological oppositions, metaphorization, disursivization is focused on the prototypical maximum of the concept of "Innovation" in contrasting "truly innovative - declared innovative" in the world of action. In the structure of the concept, based on a sustainable view of innovation as a means of modernization, actual new homeostatic nodes are being formed. They link development, progress and openness, inevitability of innovations and readiness to implement them.
\end{abstract}

Key words: axiological strategy, valorizing discourse, concept of "Innovation", trajectory of discursivization, axiological parameterization, argumentation.

Citation. Serebrennikova E.F., Sadovnikova O.N. Strategic Importance of Valorizing Discourse in the Subject Sphere of Innovation. Vestnik Volgogradskogo gosudarstvennogo universiteta. Seriya 2. Yazykoznanie [Science Journal of Volgograd State University. Linguistics], 2021, vol. 20, no. 1, pp. 158-167. (in Russian). DOI: https:// doi.org/10.15688/jvolsu2.2021.1.13

\section{СТРАТЕГИЧНОСТЬ ВАЛОРИЗИРУЮЩЕГО ДИСКУРСА В ПРЕДМЕТНОЙ СФЕРЕ ИННОВАЦИЙ}

\section{Евгения Федоровна Серебренникова}

Иркутский государственный университет, г. Иркутск, Россия

Ольга Николаевна Садовникова

Иркутский государственный университет, г. Иркутск, Россия 
Аннотация. Статья посвящена изучению стратегичности как качественной категории дискурса, характеризующей продвижение значимого смысла в медийном, аксиологически параметризованном пространстве. В рамках модели траектории дискурсивизации, обоснованной в русле динамического подхода к анализу дискурса, с применением методов интерпретативного анализа и инференции устанавливается природа стратегичности медийного дискурса, организованного целевым, актуально важным концептом Инновация, и уточняются способы ее реализации в аксиологических стратегиях, раскрывающих стратегичность дискурса. Тип дискурсного топика и интенциональность продвижения значимого смысла в векторе от мира реального к миру должного и желаемого придают данному дискурсу валоризирующий, конструирующий и предписательный характер. Проецируемые аксиологические стратегии и тактики способствуют переосмыслению и обогащению структуры концепта Инновация. В превалирующей стратегии негативной валоризации, в тактиках девалоризирующей оценочной номинации инноваций как реализованного феномена, аксиологических оппозиций, метафоризации дискурсивизация ориентирована на прототипический максимум концепта Инновация в противопоставлении «истинно инновационное - декларируемое инновационное» в мире действий. В структуре концепта на основе устойчивого представления об инновациях как средстве модернизации формируются актуально новые гомеостатические узлы, связывающие развитие, прогресс и открытость, неизбежность инноваций и готовность к их реализации.

Ключевые слова: аксиологическая стратегия, валоризирующий дискурс, концепт Инновация, траектория дискурсивизации, аксиологическая параметризация, аргументация.

Цитирование. Серебренникова Е. Ф., Садовникова О. Н. Стратегичность валоризирующего дискурса в предметной сфере инноваций // Вестник Волгоградского государственного университета. Серия 2, Языкознание. - 2021. - Т. 20, № 1. - C. 158-167. - DOI: https://doi.org/10.15688/jvolsu2.2021.1.13

\section{Введение}

Дискурс, обладая когнитивной природой и представляя собой в динамическом отношении речевое воплощение смысла, организуется процессуально [Плотникова, Серебренникова, 2013] вокруг опорного концепта [Демьянков, 2003 , с. 117], в котором заложено оценочное измерение, отражающее субъектный характер концептуализации как освоения информации [Болдырев, 2004]. В дискурсе, организованном ценностно насыщенным концептом, концептуализация осуществляется на основе оценочной деятельности субъекта по формированию ценностного отношения к референциальному миру. Дискурс такого типа является валоризирующим, поскольку в нем смыслообразование выстроено аргументативно как продвижение особо значимого смысла, и реализуется, таким образом, валоризация ценностно измеряемой дискурсивной позиции говорящего. Такое понимание дискурса, отражающее связь между концептуализацией, категоризацией и оцениванием проблемно осмысляемой ситуации, позволяет рассмотреть дискурс в модели дискурсивизации, то есть охарактеризовать траекторию развертывания от начальной точки - установок, интенциональности адресанта сообщения, проецируемых на стратегичность и аргументацию, - до достижения конечной по времени и завершающей по смыслу точки дестинации, предназначенности дискурса в коммуникации, которая активирует выбор стратегии аксиологического плана (подробно об этом см.: [Плотникова, Серебренникова, 2013 , с. 185]). Таким образом, в рамках модели траектории дискурсивизации, наряду с интенциональностью и конечной дестинацией, выделяется связывающая их качественная категория стратегичности, раскрывающаяся в определенного вида стратегиях.

Под аксиологической стратегией понимаем оптимальный способ конструирования ценностного смысла, который выводит познание объекта на новый уровень интерпретации в координатах необходимого, желаемого, должного. Реализация валоризирующего дискурса по модели дискурсивизации позволяет осмыслить конструирование ценностного смысла в нем по отношению к предмету осмысления, а также выявить изменения ценностных ориентиров осмысляемого концепта через анализ дестинации - конечной целевой доминанты, завершающей дискурсивизацию.

В современном медийном коммуникативном пространстве особо актуальными являются темы, связанные с модернизационными процессами в различных сферах 
общества, представленные в различного рода медиатекстах. Один из дискурсных топиков репрезентирован высокочастотным знаком медиатизации инновация, что дает основание выделить «дискурс об инновациях» как фрагмент медиадискурса, маркированный данным тематическим знаком, именующим концепт целевого плана Инновация. Углубленный семантический анализ показывает ценностную насыщенность концептуальной структуры, репрезентированной знаком, ценностный статус концепта [Садовникова, 2016]. Содержательно валоризирующий дискурс названной предметной сферы представляет совокупность дискурсивных позиций о сущности, способах, инструментах, рисках, возможностях, результатах инновации как синкретичного процесса - «введения в новое» состояние и одновременно инструмента данного процесса, если исходить из базового критерия внутренней формы имени этого концепта и его концептуального анализа.

Вектор реализации валоризирующего дискурса сферы инноваций направлен на оценочное конструирование наиболее значимого смысла ценностного плана путем убеждения целевого адресата в кредибильности выдвигаемой позиции по топику «инновация», порождающему прагматическую ситуацию оценочного осмысления.

Концептуальная шкалированная оппозиция «новое - более эффективное - радикально эффективное / старое - отжившее - менее эффективное - тормозящее развитие», спроецированная на дискурсивный мир, параметризирует его в базовой ценностной оппозиции, определенной В.В. Ильиным как «мир реальный - мир должный, желаемый, необходимый» [Ильин, 2005, с. 4]. В случае анализа дискурса об актуальном состоянии дел, как показывает наш материал, осмысление топиков предметной сферы инноваций сосредоточивается на «мире действий» в реализации данного базового вектора аксиологической рефлексии. В этой связи возникает вопрос о том, на основе какой стратегии структурируется текст / дискурс в соответствии с базовым ценностным параметром, если иметь в виду, что валоризации как способу реализации интепретативнооценочного аспекта дискурса [Болдырев, 2011] присуща двойственность, проявляющаяся во взаимозависимости на когнитивном уровне позитивного и негативного оценивания с ориентацией на максимум / минимум в оценочной шкале концептуализации.

Цель настоящего исследования состоит в установлении способов реализации аксиологической стратегии и дестинации как вклада в интерпретацию концепта Инновация на основе анализа медийного валоризирующего дискурса. Объектом анализа является совокупность медиатекстов предметной сферы инноваций, репрезентирующих позицию экспертного сообщества по проблемно осмысляемой ситуации референциального мира. Как валоризирующий дискурс рассмотрены политический, экономический и другие виды экспертного дискурса, в которых конструируется и выводится на новый уровень концептуализации ценностный смысл концепта Инновация.

\section{Методология и материал исследования}

Методология анализа опирается на положения о когнитивной природе дискурса в русле динамического подхода к его изучению в модели траектории дискурсивизации, на теорию ценностей и оценки [Арутюнова, 1988; Риккерт, 1998], на положения об аксиологической стратегии, заложенной в языке [Баранов, 1989], о совмещенности процессов концептуализации и оценивания в межперсональной коммуникации [Болдырев, 2011], о стратегиях понимания текста от языкового кода к базовому тексту и ситуации [Дейк, Кинч, 1989], на положения лингвоаксиологического анализа дискурса, основанного на методах интерпретационного анализа, инферировании к ценностному измерению языка, моделирования.

Источником материала для анализа послужил корпус из 55 медиатекстов предметной сферы инноваций, отобранных из интернетисточников российского, английского, китайского доменов за период 2003-2019 годы.

Изучение реализации аксиологической стратегии как целенаправленного способа продвижения особо значимого смысла в траектории дискурсивизации осуществляется нами в соответствии с когнитивной процедурой оценивания, в которую входит формулирование исходной эвалюативной оценки количественного или фактологического характера, затем 
переход к прототипической оценке и далее к гомеостатической оценке, обнаруживающей степень достижения цели (представления об успешности / неуспешности проекта, дела, деятельности) в предметной сфере инноваций. Для иллюстрации выделенных тактик из общего корпуса языкового материала на разных языках отбираются в качестве примеров наиболее репрезентативные тексты.

\section{Результаты и обсуждение}

В анализируемом типе дискурса выявляется аксиологическая стратегия с доминантой негативной валоризации, одновременно инферирующей или эксплицитно выводящей на линию позитивной валоризации. Идентификация негативной или позитивной валоризации [Caдовникова, 2018] происходит по ментальной шкале «плохо / хорошо», заложенной в языке и представляющей общее, поляризованное, ценностное измерение когнитивной системы человека.

Наш анализ раскрывает превалирование аксиологической стратегии негативной валоризации. Она основана на девалоризации имеющегося опыта по внедрению инноваций с целью продвижения на этом фоне своего видения инновационного мира будущего как концептуально-целевой сферы, за счет чего в процессе дискурсивизации происходит переосмысление концепта Инновация.

Стратегия негативной валоризации реализуется прежде всего через тактики девалоризирующей оценочной номинации, аксиологической оппозиции, девалоризации инноваций как реализовавшегося явления.

Тактика девалоризирующей оценочной номинации реализуется посредством конструирования оппозиции - негативной оценочной квалификации референтов, первично номинированных позитивно. Так, проект «Сколково» вторично номинируется следующим образом:

(1) Инноград обреченный (ИО);

(2) Город со странным названием (МИФ);

(3) «инкубатор» для эмигрантов (АН);

(4) сомнительные инновации (Версия).

В результате дискурсивизации конструируется представление о Сколково как о достаточно неудачном инновационном проекте, в котором может наблюдаться обесценивание реализованных инноваций как инструментов, не отвечающих запросу на внесение качественных, долгосрочных, прогрессивных изменений в существующее положение дел. На стыке биполярных оценок целевая область «новое», включенная в концепт Инновация, имплицирует шкалу оценки, ориентированную на прототипический максимум - «истинностно новое», и градуирует тем самым осмысление реализованного «нового» с оценкой «+/-». Превалирование на эксплицитном уровне негативной оценочной квалификации, валоризируя концептуальную позицию адресанта по отношению к дискурсному топику, структурирует новый узел в структуре концепта Инновация, маркируемый гомеостатической оценкой «реализованные (обреченные, странные, принудительные) инновации / инновации истинностные, должные, желаемые». Тем самым аксиологическая стратегия осуществляется посредством когнитивной процедуры оценивания от исходной прототипической оценки к гомеостатической оценке.

Высокочастотный прием тактики девалоризирующей оценочной номинации составляет метафоризация, которая обнаруживается в текстах аналитического и публицистического плана. Например:

(5) ...Инновации «отклеиваются» от российской экономики, как виниловые обои от кирпичной кладки (АН).

В помощью метафоры концептуализация переносится в прототипическую сферу обыденного, всем понятного опыта. Тем самым метафора структурирует аргумент, выявляющий, по мнению адресанта, правду о сути происходящего. В отдельных случаях метафора может сочетаться с количественной оценкой в аргументации, например:

(6) Инвестировав в инновации более 2 трлн рублей и не достигнув ни одной цели, правительство уже готово бросить любимую игрушку (АН),

и структурировать ироничную тональность дискурса. Когнитивная процедура оценивания выстраивается через переход от количественной оценки, которая маркируется конкретными цифрами (более 2 трлн рублей) к гомеостатической оценке, которая отражает 
результат деятельности по развитию инноваций (не достигнув ни одной цуели, бросить любимую игрушку).

Примеры демонстрируют, что метафора как аргумент в продвижении концептуальной позиции адресанта структурирует новый узел в структуре концепта Инновация - «естественность - искусственность» инноваций.

Другой тактикой стратегии негативной валоризации является тактика аксиологической оппозиции, которая заключается в подаче информации по принципу антитезы «плюс-минус», противопоставления «своего» и «чужого» с целью валоризации наиболее эффективного способа действий, что особенно явно проявляется в китайском медиадискурсе:

(7) 开放带来进步，封闭必然落后。<..>纵 观国际经贸发展史, 深刻验证了“相通则共进, 相 闭则各退” 的规律。各国削减壁垒、扩大开 放, 国际经贸就能打通血脉; 如果以邻为壑、孤 立封闭，国际经贸就会气滞血瘀，世界经济也难 以健康发展 (CIIE)-Открытость приносит прогресс, закрытость непременно приводит к отставанию. < . .> Окидывая взором историю развития международной торговли и экономики, можно подтвердить правило «Если двигаться вместе, то все продвинутся вперед, если закрыться друг от друга, то каждый отойдет назад». Если все страны уменьшат препятствия, расширят открытость, то международная экономика сможет установить кровные связи; если решать свои проблемы за чужой счет, закрыться в изоляции, то международная торговля придет к застою и мировой экономике будет невозможно нормально развиваться ${ }^{1}$.

В данном примере открытость предстает как обязательный элемент развития, тем самым эксплицируется прототипическая оценка, которая переходит в гомеостатическую, формируя представления о возможных способах достижения успешности в данной предметной сфере. Маркером гомеостатической оценки является 进步 (прогресс) как цель и результат по внедрению инноваций. Аргументация осуществляется посредством аналогии и путем метафорического переноса осмысления в сферу нормальной жизнедеятельности человека: 打通血脉 (открыть доступ к кровообращению; установить кровные связи) и 气滞血瘀 (стагнация жизненной энергии (Ци) и крови). Антиномия открытости и закрытости, стагнации и энергичности валоризует ценность сотрудничества, готовности к модернизации как нормальному и необходимому процессу. Противопоставление в метафоричной, образной форме особенно типично для китайской лингвокультуры:

(8) 封闭的空间只会四处碰壁, 开放的道路 才会越走越宽。(CICA) - Закрытое пространство может только упереться в глухую стену, и только открытая дорога будет становиться все шире и шире.

Таким образом, путем метафорического противопоставления осуществляется возведение концептуализации инноваций в аксиологически более обобщенный формат знания.

Аксиологическая оппозиция способствует продвижению экспертной позиции по поставленному вопросу также в деонтическом, предписательном ключе в русскоязычных медиатекстах:

(9) Нужно не менять страну, а построить новую, если большая часть страны противится инновациям (МИФ).

В качестве аргумента предлагается сценарий будущего, фактором которого является принятие инноваций, - построить новую страну. Выдвижение идеи по внедрению инноваций осуществляется на оценочном основании осмысления реальности - девалоризации уже реализованных действий (неприятие инноваций). В английской лингвокультуре тактика аксиологической оппозиции реализуется при помощи диалектических, выстраивающих альтернативу, риторических вопросов к аудитории:

(10) Will we accept an economy where only a few of us do spectacularly well? Or will we commit ourselves to an economy that generates rising incomes and chances for everyone who makes the effort? (TIME) - Примем ли мы экономику, в которой лишь некоторые из нас преуспевают? Или мы возьмем на себя обязательство создать экономику, обеспечивающую рост доходов и шансов для всех, кто прилагает усилия?

Такой способ подачи информации включает адресата в процесс принятия решений, а через использование операторов шкалирования с количественной оценкой $a$ few, rising направляет вектор размышления над будущим страны в нужную адресанту сторону. 
Стратегия негативной валоризации реализуется также посредством тактики структурирования нарратива, то есть представления о явлении в его прошлом, обусловившем его настоящее с проекцией на его желаемое будущее. Прошлое конструируется в основном глаголами прошедшего времени:

(11) Нам обещали, что Город (Сколково. E. C., O. C.) все изменит. <..> ...Государство пыталось создать в России рынок венчурных инвестиций в технологические стартапы (МИФ).

В данном примере глаголы прошедшего времени обещали, пыталось девалоризуют действия по созданию инновационного центра «Сколково», при этом профилируется признак 'развитие', входящий в структуру концепта Инновация. Глаголы прошедшего времени также употребляются в метафоричных выражениях и часто сопровождаются экземплификацией в аргументации:

(12) В 2012 г. умы снова стали паковать чемоданы: из России уехали 5700 дипломированных специалистов (АН).

Девалоризация инновационного опыта России достигается путем эвалюации оттока лучших специалистов в 2012 г., а также посредством метонимии умы стали паковать чемоданы. Тем самым инферируется идея необходимости сохранения лучших кадров для инновационного будущего страны.

Глаголы прошедшего времени, структурирующие нарратив, могут употребляться по градации в базовой аксиологической оппозиции «свой - чужой» для наиболее эффективного формулирования ценностных смыслов:

(13) There have been those who told us to fear the future, who claimed we could slam the brakes on change, who promised to restore past glory if we just got some group or idea that was threatening America under control. And each time, we overcame those fears (CBS) - Были те, кто говорил нам бояться будущего, кто утверждал, что мы можем затормозить перемены, кто обещал восстановить былую славу, если мы просто возьмем под контроль некую группу или идею, угрожающую Америке. И каждый раз мы преодолевали эти страхи.

Как видим, с помощью глаголов прошедшего времени, выстроенных в градации (told, claimed, promised), и маркеров оппозиции «свой - чужой», личных местоимений (those who-us, we) дается негативная оценка действиям внешних сил и валоризуются действия американцев в прошлом по улучшению качества жизни.

Результирующим этапом реализации стратегии негативной валоризации является вынесение заключительного суждения о сущности и ценности инноваций - переход к собственно когнитивным и прагматическим оценкам. Тем самым профилируется дестинация дискурса, которая нацелена на конструирование таких аксиологических параметров ситуации, которые апеллируют в коммуникативном пространстве к необходимости изменения реальности. Посредством реализации стратегии негативной валоризации и отдельных тактик в критическом векторе размышления говорящий стремится представить новое видение инноваций как основы стратегической инициативы для страны, мегапроекта, нацеленного в будущее, например:

(14) ...Основы стратегической инициативы для страны, мегапроекта, нацеленного в будущее: Для полноценной реализации стратегической инновационной инициативы сегодня необходима не только и не столько пресловутая политическая воля, сколько понимание и системная поддержка мегапроекта со стороны влиятельных политических и экономических кругов, его одобрение населением страны, конструктивная позиция зарубежных партнеров. Нужна при этом и соответствующая широкая информационная кампания. В случае реализации этих условий российская стратегическая инновационная инициатива может быть подана как основа для формирования новых правил игры (ЭС).

Адресант определяет реализацию программы эффективных действий для осуществления стратегической инновационной инициативы России условиями: проведением информационной кампании, наличием системной поддержки, одобрением населения страны. Выдвижение данных требований для достижения целей «мира ценностного, должного и необходимого» конструируется в контрасте с «миром действий». Транслируемый смысл поляризует мир, проецирует его аксиологический рефрейминг, представляя желаемое, должное будущее через позитивные категории (систем- 
ная поддержка, одобрение, конструктивная позиция и т.д.) и показывая мир реальный в негативном ключе (пресловутая политическая воля). Целевая доминанта, маркирующая завершение дискурсивизации, формулируется в виде оппозиции и может быть представлена имплицитно и эксплицитно:

(15) 变革创新是推动人类文明进步的强大 动力。我们要顺应时代变化, 把勇于革新的理念 落实到行动层面, 加强理论、制度、科技、文化 等各方面创新, 永葆亚洲发展活力。要敢于推陈 出新, 努力为解决老问题寻找新答案, 为应对 新问题寻找好答案, 破解亚洲面临的各类难题 (CICA) - Преобразования и инновации - основная движущая сила, подталкивающая человеческое общество вперед к развитию. Мы должны идти в ногу со временем и изменяться, ввести идею смелого создания инноваций на новый уровень, усилить инновации в теории, системе, науке и технике, культуре и во всех сферах, чтобы сохранить жизненную силу развития Азии. Нужно быть готовым оставлять старое позади и внедрять новое, стараться искать новые ответы на старые вопросы, искать хорошие ответы на новые вопросы, разъяснять различные сложные вопросы, стоящие перед Азией.

На фоне ведущей оппозиции 老 - 新 (старый новый) и с помощью модального оператора долженствования 要 (нужно) говорящий эксплицитно продвигает идею желаемого и должного будущего, выражает готовность и стремление к сотрудничеству, совместной работе и вовлечению в модернизационные процессы как государства, так и аудитории, для которой предназначено данное выступление. Как следствие, дестинацией высказывания является представление способа изменения отношения к инновациям.

\section{Выводы}

Аксиологический анализ валоризирующего дискурса предметной сферы инноваций позволил выявить параметры реализации стратегичности дискурса данного типа, а также способы его структурирования, которые основаны на девалоризации признаков, образующих актуальную ценностную структуру концепта Инновации. Ведущей стратегией аргументации в конструировании оценочного отношения является стратегия негативной валоризации инновации как элемента мира реальности с проекцией на мир должного, желаемого, необходимого. Данный вид аксиологической стратегии, которая может быть названа контрастной, реализуется посредством тактики девалоризирующей оценочной номинации на основе приемов негативной оценочной квалификации, метафоризации, структурирования нарратива (ретроспекции ожидаемого желаемого настоящего и будущего путем реконструкции прошлого). Когнитивная процедура оценивания в траектории дискурсивизации осуществляется в основном через переход от исходной количественной оценки к прототипической оценке, которая имплицирует шкалу оценки и тем самым реализует переход к гомеостатической оценке, которая отражает представления говорящего об успешности инновационной деятельности.

Базовым механизмом контрастной негативной валоризации является структурирование аксиологической оппозиции, которая реализуется посредством как противопоставления отдельных признаков концепта Инновации, так и более общего, метафорического противопоставления. Критический вектор рассуждения и аргументации высвечивает на когнитивном уровне позитивную дестинацию, которая заключается в рефрейминге предмета осмысления в контрастном ключе. В результате медийной оценочной концептуализации на основе аксиологической стратегии продвижения наиболее значимого смысла и когнитивной процедуры оценивания в модели «количественная оценка $\rightarrow$ прототипическая оценка $\rightarrow$ гомеостатическая оценка» конструируются новые узлы в структуре концепта Инновация, профилирующие такие признаки, как «истинностное-реализованное», «естественное - искусственное», «нормальное - анормальное».

Таким образом, стратегичность медийного дискурса об инновациях имеет валоризирующий, конструктивный и предписательный характер. Проецируемые аксиологические стратегии и тактики способствуют переосмыслению и обогащению структуры концепта Инновация. В превалирующей стратегии негативной валоризации, в тактиках девалоризирующей оценочной номинации инноваций как реализованного феномена, аксиологических оппозиций, метафоризации 
целевой адресат ориентируется на прототипический максимум концепта Инновация в аспектах противопоставления «истинно инновационное - декларируемое инновационное» в мире действий. В структуре концепта Инновация формируются актуально новые гомеостатические узлы, связывающие развитие, прогресс и открытость, неизбежность инноваций и готовность к их реализации.

\section{ПРИМЕЧАНИЕ}

1 Здесь и далее перевод с китайского и английского языков О.Н. Садовниковой.

\section{СПИСОК ЛИТЕРАТУРЫ}

Арутюнова Н. Д., 1988. Типы языковых значений: Оценка. Событие. Факт. М. : Наука. 341 с.

Баранов А. Н., 1989. Аксиологические стратегии в структуре языка (паремиология и лексика) // Вопросы языкознания. № 3. С. 74-90.

Болдырев Н. Н., 2004. Свойства и границы оценочных категорий в свете новых представлений о процессах категоризации // Языковые категории: границы и свойства : материалы Междунар. науч. конф. (Минск, 22-23 марта 2004 г.). Минск : МГЛУ. С. 14-16.

Болдырев Н. Н., 2011. Интерпретирующая функция языка // Вестник Челябинского государственного университета. Серия: Филология. Искусствоведение. № 33 (248). С. 11-16.

Дейк Т. А. ван, Кинч В., 1989. Макростратегии // Язык. Познание. Коммуникация. М. : Прогресc. C. 41-67.

Демьянков В. 3., 2003. Интерпретация политического дискурса в СМИ // Язык СМИ как объект междисциплинарного исследования. М. : Изд-во Моск. гос. ун-та им. М.В. Ломоносова. C. $116-133$.

Ильин В. В., 2005. Аксиология. М. : Изд-во МГУ. $216 \mathrm{c}$.

Карасик В. И., 2002. Языковой круг: личность, концепты, дискурс. Волгоград : Перемена. 477 с.

Плотникова С. Н., Серебренникова Е. Ф., 2013. Когнитивная траектория дискурсивизации: дестинация, стратегия, технология // Вестник Иркутского государственного лингвистического университета. № 1. С. 183-188.

Риккерт Г., 1998. О системе ценностей // Риккерт Г. Науки о природе и науки о культуре. М. : Республика. С. 363-391.

Садовникова О. Н., 2016. Инновация: этносемиометрия знака в русском и китайском языках: сравнительные параллели // Проблемы устойчивого развития гуманитарных и естественных наук : аспирант. чтения. Иркутск : МГЛУ ЕАЛИ. С. 192-200.

Садовникова О. Н., 2018. Аксиологические стратегии дискурса об инновациях и способы их аргументации // Вестник Кемеровского государственного университета. № 3. С. 210-216.

\section{ИСТОчники}

$A H$ - Терентьев Д. Молоко без коровы. Почему России не удается построить инновационную экономику // Аргументы Недели. № 4 (546). URL: https://argumenti.ru/economics/ n575/521042 (дата обращения: 14.11.2019).

Версия - Горевой Р. Как выбрасывают государственные миллиарды на сомнительные инновационные проекты // Версия. URL: https:// versia.ru/kak-vybrasyvayut-gosudarstvennyemilliardy-na-somnitelnye-innovacionnyeproekty (дата обращения: 14.11.2019).

ИО - Носырев И. Инноград обреченный // Тhe New Times. URL: https://newtimes.ru/articles/ detail/29569/ (дата обращения: 14.11.2019).

МИФ-Рашидов О. Сколково: принуждение к чуду. Реальная история создания самого амбициозного проекта в России. М. : Манн, Иванов, Фербер, 2012. 256 с.

ЭС - Неклесса А. И., Щедровицкий П. Г. Инновационная Россия // Экономические стратегии. № 5. 2003 С. 30-35. URL: https:// shchedrovitskiy.com/innovacionnaja-rossija/ (дата обращения: 14.11.2019).

CBS - Barack Obama. Transcript: State of the Union 2016// CBS NEWS. URL: http://www.cbsnews. com/news/transcript-state-of-the-union-2016/ (date of access: 14.11.2019).

$C I C A-\mathrm{Xi}$ Jinping. Transcript: Speech at the $5^{\text {th }}$ Summit of the Conference on Interaction and Confidence-Building Measures in Asia (CICA) // Xinhua News Agency Dushanbe. URL: http://www.xinhuanet.com/world/201906/15/c 1124627485.htm (date of access: 14.11.2019).

CIIE - Xi Jinping. Transcript: Building an Innovative and Inclusive Open World Economy - Speech at the Opening Ceremony of the First China International Import Expo // President of the People's Republic of China Xi Jinping. URL: https://www.ciie.org/zbh/cn/IEF/ important/20190827/18141.html (date of access: 14.11.2019).

TIME - Barack Obama. The Full Text of President Obama's 2015 State of the Union // Time. URL: http://time.com/3675705/full-text-stateunion-2015/ (date of access: 14.11.2019). 


\section{REFERENCES}

Arutyunova N.D., 1988. Tipy yazykovykh znacheniy: Otsenka. Sobytie. Fakt [Types of Language Meanings. Evaluation. Event. Fact]. Moscow, Nauka Publ. 341 p.

Baranov A.N., 1989. Aksiologicheskie strategii v strukture yazyka (paremiologiya i leksika) [Axiological Strategies in the Structure of Language (Paremiology and Lexis)]. Voprosy yazykoznaniya [Topics in the Study of Language], no. 3, pp. 74-90.

Boldyrev N.N., 2004. Svoystva i granitsy otsenochnykh kategoriy $\mathrm{v}$ svete novykh predstavleniy o protsessakh kategorizatsii [Properties and Boundaries of Evaluation Categories in the Light of New Ideas About Categorization Processes]. Yazykovye kategorii: granitsy $i$ svoystva: materialy Mezhdunar. nauch. konf. (Minsk, 22-23 marta 2004) [Language Categories: Boundaries and Properties: Proceedings of the International Scientific Conferences (Minsk, March 22-23, 2004)]. Minsk, MGLU, pp.14-16.

Boldyrev N.N., 2011. Interpretiruyushchaya funktsiya yazyka [Interpreting Function of the Language]. Vestnik Chelyabinskogo gosudarstvennogo universiteta. Seriya: Filologiya. Iskusstvovedenie [Bulletin of Chelyabinsk State University. Languages and Literature], no. 33 (248), pp. 11-16.

Deyk T.A. van, Kinch V., 1989. Makrostrategii [Macrostrategy]. Yazyk. Poznanie. Kommunikatsiya [Language. Cognition. Communication]. Moscow, Progress Publ., pp. 41-67.

Demyankov V.Z., 2003. Interpretaciya politicheskogo diskursa v SMI [Interpretation of Political Discourse in the Media]. Yazyk SMI kak obyekt mezhdistsiplinarnogo issledovaniya [Media Language as an Object of Interdisciplinary Research]. Moscow, Izd-vo Moskovskogo gosudarstvennogo universiteta im. M.V. Lomonosova, pp. 116-133.

Ilyin V.V., 2005. Aksiologiya [Axiology]. Moscow, Izd-vo MGU. 216 p.

Karasik V.I., 2002. Yazykovoy krug: lichnost, kontsepty, diskurs [Language Circle: Personality, Concepts, Discourse]. Volgograd, Peremena Publ. 477 p.

Plotnikova S.N., Serebrennikova E.F., 2013. Kognitivnaya traektoriya diskursivizatsii: destinatsiya, strategiya, tekhnologiya [The Cognitive Trayectory of Discursivization: Destination, Strategy, Technology]. Vestnik Irkutskogo gosudarstvennogo lingvisticheskogo universiteta [ISLU Philological Review], no. 1, pp. 183-188.

Rikkert G., 1998. O sisteme tsennostey [About the Value System]. Nauki o prirode i nauki o kulture
[The Natural Sciences and Cultural Sciences]. Moscow, Respublika Publ., pp. 363-391.

Sadovnikova O.N., 2016. Innovatsiya: etnosemiometriya znaka v russkom i kitayskom yazykakh: sravnitelnye paralleli [The Innovation: Ethnosemiotics of the Sign in Russian and Chinese: A Comparative Parallel]. Problemy ustoychivogo razvitiya gumanitarnykh i estestvennykh nauk: aspirant. chteniya [Problems of Sustainable Development of the Humanities and Natural Sciences: Postgraduate Reading]. Irkutsk, MGLU EALI, pp. 192-200.

Sadovnikova O.N., 2018. Aksiologicheskie strategii diskursa ob innovatsiyakh i sposoby ikh argumentatsii [The Axiological Strategies of Innovation Discourse and Ways of Their Argumentation]. Vestnik Kemerovskogo gosudarstvennogo universiteta [Bulletin of Kemerovo State University], no. 3, pp. 210-216.

\section{SOURCES}

Terentev D. Moloko bez korovy. Pochemu Rossii ne udayotsya postroit innovatsionnuyu ekonomiku [Milk Without a Cow. Why Russia Fails to Build an Innovative Economy]. Argumenty Nedeli [Arguments of the Week], no. 4 (546). URL: https://argumenti.ru/economics/n575/521042 (accessed 14 November 2019).

Gorevoy R. Kak vybrasyvayut gosudarstvennye milliardy na somnitelnye innovatsionnye proekty [How to Throw State Billions on Dubious Innovation Projects]. Versiya [Version]. URL: https://versia. ru/kak-vybrasyvayut-gosudarstvennye-milliardyna-somnitelnye-innovacionnye-proekty (accessed 14 November 2019).

Nosyrev I. Innograd obrechennyy [The Doomed Innograd]. The New Times. URL: https:// newtimes.ru/articles/detail/29569/ (accessed 14 November 2019).

Rashidov O. Skolkovo: prinuzhdenie k chudu. Real'naja istorija sozdanija samogo ambicioznogo proekta $v$ Rossii [Skolkovo: Coercion to a Miracle. The Real Story of the Creation of the Most Ambitious Project in Russia]. Moscow, Mann, Ivanov, Ferber Publ., 2012. 256 p.

Neklessa A.I., Shhedrovickij P.G. Innovatsionnaya Rossiya [Innovative Russia]. Ekonomicheskie strategii [Economic Strategies], no. 5. 2003, pp. 30-35. URL: https://shchedrovitskiy.com/ innovacionnaja-rossija/ (accessed 14 November 2019).

Barack Obama. Transcript: State of the Union 2016. CBS NEWS. URL: http://www.cbsnews.com/news/ transcript-state-of-the-union-2016/ (accessed 14 November 2019). 
Xi Jinping. Transcript: Speech at the $5^{\text {th }}$ Summit of the Conference on Interaction and ConfidenceBuilding Measures in Asia (CICA). Xinhua News Agency Dushanbe. URL: http://www.xinhuanet. com/world/2019-06/15/c_1124627485.htm (accessed 14 November 2019).

Xi Jinping. Transcript: Building an Innovative and Inclusive Open World Economy - Speech at the Opening Ceremony of the First China
International Import Expo. President of the People's Republic of China Xi Jinping. URL: https://www.ciie.org/zbh/cn/IEF/ important/20190827/18141.html (accessed 14 November 2019).

Barack Obama. The Full Text of President Obama's 2015 State of the Union. Time. URL: http:// time.com/3675705/full-text-state-union-2015/ (accessed 14 November 2019).

\section{Information About the Authors}

Evgenia F. Serebrennikova, Doctor of Sciences (Philology), Professor, Department of Romano-Germanic Philology, Irkutsk State University, Karla Marksa St, 1, 664003 Irkutsk, Russia, serebr_ef_76@mail.ru,https://orcid.org/0000-0002-3910-4013

Olga N. Sadovnikova, Postgraduate Student, Department of Romano-Germanic Philology, Senior Lecturer, Department of Oriental and Area Studies in the APR, Irkutsk State University, Karla Marksa St, 1, 664003 Irkutsk, Russia, olgasdvnkv@gmail.com, https://orcid.org/0000-0003-4197-5552

\section{Информация об авторах}

Евгения Федоровна Серебренникова, доктор филологических наук, профессор кафедры романо-германской филологии, Иркутский государственный университет, ул. Карла Маркса, 1, 664003 г. Иркутск, Россия, serebr_ef_76@mail.ru, https://orcid.org/0000-0002-3910-4013

Ольга Николаевна Садовникова, аспирант кафедры романо-германской филологии, старший преподаватель кафедры востоковедения и регионоведения Азиатско-Тихоокеанского региона, Иркутский государственный университет, ул. Карла Маркса, 1, 664003 г. Иркутск, Россия, olgasdvnkv@gmail.com, https://orcid.org/0000-0003-4197-5552 